\title{
1008 低レイノルズ数における NACA0012 翼型の伴流測定 \\ Wake flow measurements of NACA0012 airfoil at low Reynolds numbers
}

\author{
○学 井上 直樹（日大理工院）正 松本 彰（日大理工）
}

\author{
Naoki INOUE and Akira MATSUMOTO
}

College of Science \& Technology, Nihon University, 1-8 Kanda, Surugadai, Chiyoda-ku, Tokyo

\begin{abstract}
We investigate the wake flow field produced by NACA0012 wing section using hot-wire anemometer at low Reynolds number, and compare the mean velocity profiles at chord Reynolds number 1000 to those at chord Reynolds number of 2000. The discontinuous point appears in the mean velocity profiles of cross-flow direction at high angle of attack at chord Reynolds number of 1000 , but it does not appear at chord Reynolds number of 2000. This is because the leading-edge separation occurs. Moreover, we measure the fluctuation velocity profiles and the vortex shedding phenomena. As a result, we found that the fluctuation velocity is composed of the relatively high amplitude and low-frequency components, and Roshko numbers are almost the same as that of the circular cylinder at an appropriate Reynolds number regime.
\end{abstract}

Key Words: Wake measurement, Wing section, Low Reynolds number

1.はじめに

近年、低レイノルズ数における翼の研究が盛んに 行われている。そこで、我々は昨年度からI 型熱線 プローブを用いて、コードレイノルズ数 Rec $=1000$ においてNACA0012 翼型の伴流構造を調べている。 1)今年度は単一傾斜熱線プローブを用いてより詳し く伴流を測定し、Rec=1000と 2000 での実験結果の 比較を行うと共に、迎角による渦発生周波数の変化 を調べた。

\section{2、実毁装置および実䍄方法}

本研究に使用した風洞は吹き出し型で測定部は $250[\mathrm{~mm}] \times 250[\mathrm{~mm}]$ の断面を持ち、長さは $600[\mathrm{~mm}]$ である。測定部入り口から $200[\mathrm{~mm}]$ の断面中心が翼 模型の翼端中心となるようにし、座標軸原点とした。 そして流れ方向をX軸、これと垂直にそれぞれ水平 方向に $\mathrm{Y}$ 軸、鉛直方向に $\mathrm{Z}$ 軸とした。また、それ

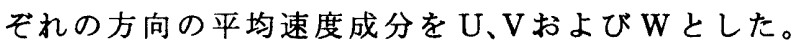

速度分布測定には単一傾斜熱線プローブ（傾斜角 $45^{\circ}$ 、直径 $5[\mu \mathrm{m}]$ の タングステン線）と、I 型熱線 プローブ(直径 $2.5[\mu \mathrm{m}]$ のタングステン線)を使用し た。また、供試翼は翼弦長 $\mathrm{c}=50[\mathrm{~mm}]$ 、最大翼厚

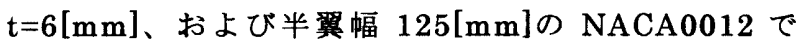
ある。

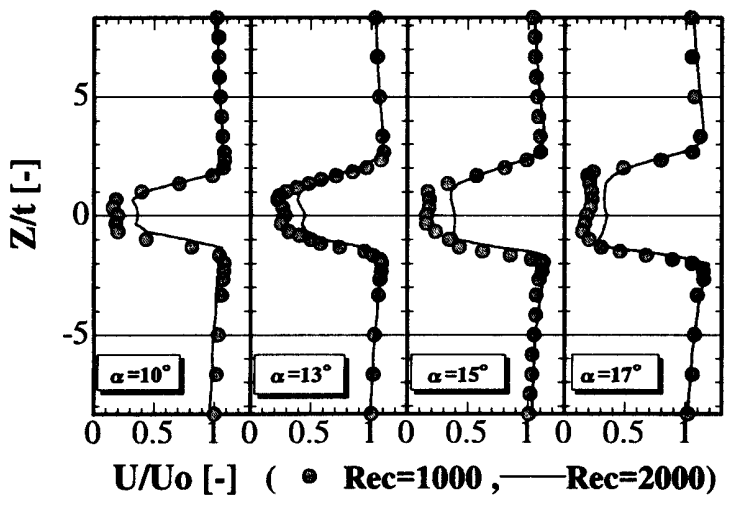

Fig.1 Mean velocity distributions of free stream direction in the wake of the wing $(\mathrm{X} / \mathrm{c}=0.6, \mathrm{Y} / \mathrm{c}=1.5)$

\section{3.実結果および考察}

Fig. 1 は X/c=0.6,Y/c=1.5における、迎角 $\alpha$ の変化 に対する U/Uoの Z 方向分布である。 Y/c=1.5 は昨 年度までの研究で、翼端渦の影響をほとんど受けな い事が分かっている位置である。丸印で示したのが $\operatorname{Rec}=1000$ の結果、一点鎖線で示したのが Rec $=2000$ の結果である。Rec にかかわらず、 $\alpha$ の增加に伴い U/Uo 分布の最大欠損部は徐々に扁平になる。さら に、 $\alpha=13^{\circ}$ まではほほ対称の分布を示し、二次元 円柱のような鈍頭物体に近い特性を示す。しかし、 $\alpha \geqq 15^{\circ}$ になると対称性はくずれ、扁平部分が翼上 面側に偏ってくる。また、Rec=2000の方が 1000 の 時よりも、速度欠損の最大值が小さくなる。

この U/Uo 分布に対応して、Fig.2 に示す W/Uo 分布は $\alpha \leqq 13^{\circ}$ では $\mathrm{Z} / \mathrm{t}=0$ を中心としてほほ点対称 形となる。これは翼上面では上から下への流れが、 翼下面ではその逆の流れが存在することを示してい る。ここでは示していないが、 $\mathrm{X} / \mathrm{c}=1.0, \mathrm{Y} / \mathrm{c}=1.5$ でも 同様の結果を得ている。しかし $\alpha \geqq 15^{\circ}$ となると、 Rec $=1000$ では W/Uo 分布に破線で示した不連続点 が現れる。この不連続点は前縁剥離に対応している と考えられる。しかしながら Rec=2000では同じ迎 角でも不連続点は現れない。

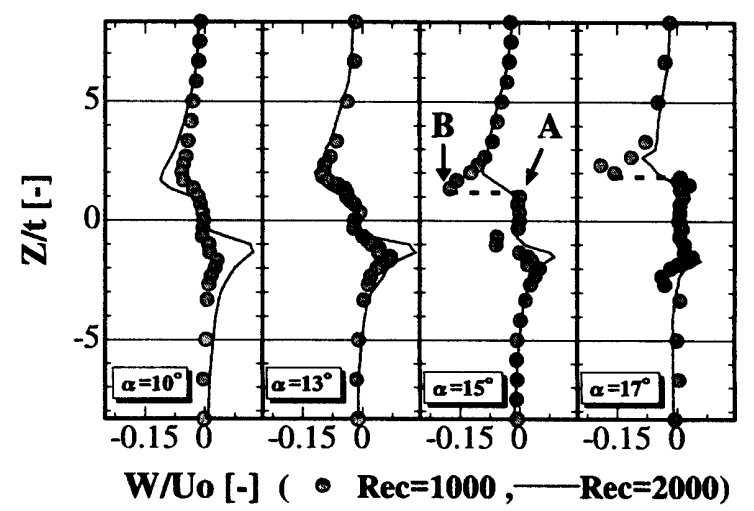

Fig.2 Mean velocity distributions of cross-flow direction in the wake of the wing $(\mathrm{X} / \mathrm{c}=0.6, \mathrm{Y} / \mathrm{c}=1.5)$ 
以降に示すのは I 型プローブを用いた実験結果である。 Fig. 3 は Fig.2 で示した様に、Rec $=1000, \alpha=15^{\circ}$ で見ら れた不連続点前後の位置 $\mathrm{A}$ 点、B 点での瞬時速度 Ui の 時間変化である。W/Uo が大きな B 点では、Ui の中に振 幅の大きな周期的変動が見られるが、W/Uo がほぼ 0 と なる $\mathrm{A}$ 点では $\mathrm{B}$ 点に比べて、振幅の小さい不規則な変動 となっている。この 2 点間で見られる不連続な特性の違 いは前縁剥離によるものだと考えられる。そこで、 Fig.2で不連続点が見られた Rec $=1000 、 \alpha=15^{\circ}$ と不連 続点が見られない $\alpha=10^{\circ}$ において、X を変化させたと きの U/Uo の Z 方向分布を Fig.4 に示す。黒丸で示した $\alpha=15^{\circ}$ の分布は灰色の丸で示した $\alpha=10^{\circ}$ の分布に比 べ、翼弦長中心位置となる X/c=0で、すでに大きな逆流 域が見られる。さらに翼伴流の平均速度分布も $\alpha=10^{\circ}$ に比べ、 $\alpha=15^{\circ}$ の方が翼の上面側の速度欠損が大きく なっている。Fig.5 は Fig.4 と同じ測定位置での変動速度 $\mathbf{u}^{\prime} / \mathrm{Uo}_{0}\left(\mathrm{u}^{\prime}\right.$ は変動速度 $\mathrm{u}$ の実効値)の $\mathrm{Z}$ 方向分布である。 $\alpha$ $=10^{\circ}$ では翼上面位置となる $\mathrm{X} / \mathrm{c}=0, \mathrm{X} / \mathrm{c}=0.4$ で速度の変 動はほとんど見られない。これに対して、 $\alpha=15^{\circ}$ では $\mathrm{X} / \mathrm{c}=0$ で約 $1.2 \% 、 \mathrm{X} / \mathrm{c}=0.4$ で約 $7 \%$ の主流に対する変動

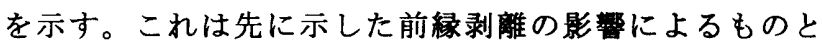
考えられる。この影響は翼伴流にもおよび、 $\alpha=15^{\circ}$ の 方が $\alpha=10^{\circ}$ に比べ、そのピーク值、面積共に大きくな っている。特に Fig.2 で不連続点が見られた X/c=0.6の 測定位置では、その違いが顕著に現れている。

これらの速度変動は迎角によって異なった卓越周波数 を持つことを示す。Fig.6 は X/c=1.0、Y/c=1.5 の位置で 翼の $\alpha$ を変化させた時、最も規則的な速度変動を示す $\mathrm{Z}$ 位置で卓越周波数 $\mathrm{f}$ を測定し、これから計算した Roshko 数 $\mathrm{Ro}_{0}$ である。 $\left(\mathrm{Ro}_{\mathrm{o}}=\mathrm{fd}^{2} / v: \mathrm{d}\right.$ は主流方向に垂直な翼の長 さ、 $v$ は動粘性俰数） $\operatorname{Rec}=1000$ では $\alpha \doteqdot 8^{\circ} \sim 23^{\circ}$ 、 $\mathrm{Rec}=2000$ では $\alpha \doteqdot 2^{\circ} \sim 15^{\circ}$ で卓越した周波数をもつ 速度変動が見られた。また、横軸の Red はdを基準にと ったレイノルズ数である。 Red=約 $150 〜 400$ では NACA0012のRoは四角印と点線で示した Huang らの 翼伴流の実験值 2)よりも、実線で示した Roshkoによる 円柱の実験式に近い值をとった。これは上のレイノルズ 数の範囲では、翼が 2 次元鈍頭物体である円柱に近い剥 離特性を示しているためと考えられる。

4.まとめ

今回の測定で以下の事がわかった。

(1) $\operatorname{Rec}=1000,2000$ ともに翼伴流のU成分の Z方向分布 は $\alpha=13^{\circ}$ 以下ではほほ対称形ととなるが、 $\alpha$ $=15^{\circ}$ 以上では対称形がくずれ、死水領域を示す速度 の最大欠損の扁平部分が翼上面側に広がってくる。

(2) $\operatorname{Rec}=1000$ では W 成分の $\mathrm{Z}$ 方向分布に $\alpha=15^{\circ}$ 以上 において不連続点が現れるが、Rec $=2000$ では現れ ない。

（3）（1）の $\alpha=15^{\circ}$ 以上における速度分布が非対称となる のは翼前縁での流れの剥離によるものであることが わかった。

（4） Red=約 150〜 400 では Roshko 数は 2 次元鈍頭物体 である円柱の值に近いことが分かった。

\section{参考文苚}

1)井上直樹・松本彰:日本機械学会九州支部講演論文集、 No.018-1(2001),pp 145-146

2) Rong F.Huang and Han W. Lee : AIAA JOURNAL Vol.38,No.1,January 2000,pp87-94

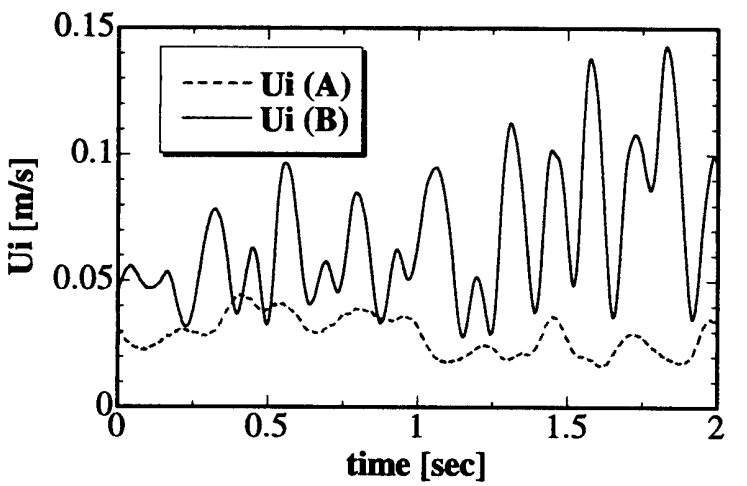

Fig.3 Time history of instantaneous velocities Ui $(\mathrm{X} / \mathrm{c}=\mathbf{0 . 6}, \mathrm{Y} / \mathrm{c}=1.5, \operatorname{Rec}=1000)$

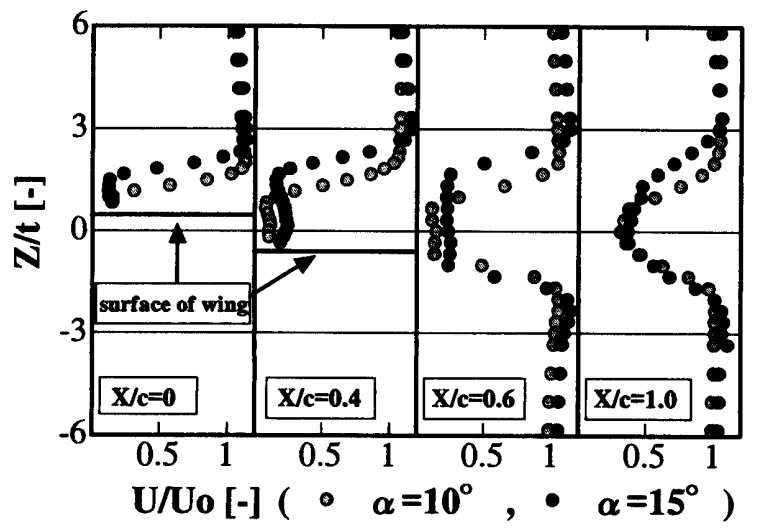

Fig.4 Mean velocity distributions in the wake of the wing $\quad(Y / c=1.5, \operatorname{Rec}=1000)$

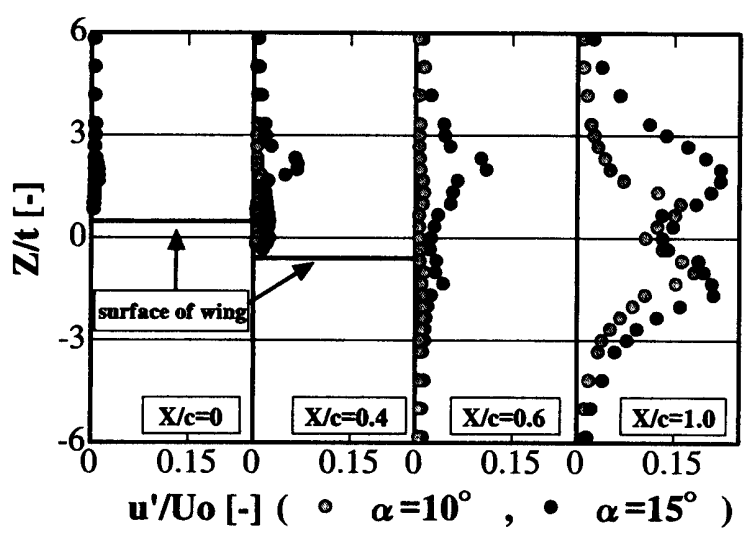

Fig.5 Fluctuating velocity distributions in the wake of the wing $\quad(Y / c=1.5, \operatorname{Rec}=1000)$

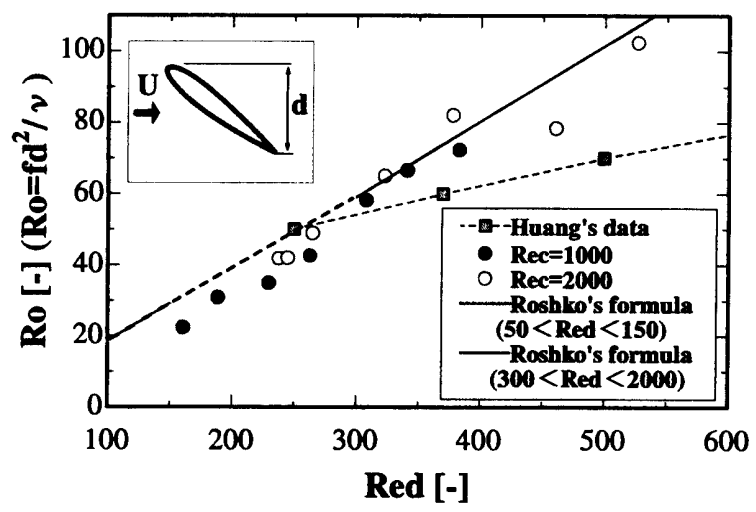

Fig.6 Roshko number (Vortex shedding parameter) vs. Reynolds number $(X / c=1.0, Y / c=1.5)$ 